\title{
A Good Samaritan: A Patient, a Colleague, or a Mentor
}

\author{
Vikas Suri $^{1}$, Deepti Suri ${ }^{2}$, Ashish Bhalla ${ }^{3}$, Ritin Mohindra ${ }^{4}$, Savita Kumari ${ }^{5}$ \\ Journal of Postgraduate Medicine Education and Research (2020): 10.5005/jp-journals-10028-1385
}

It was late February when the news of coronavirus disease-2019 (COVID-19) pandemic had just started creating ripples world over. Like many other countries, we in India were quite unsure about what was in store for us. A few patients had been reported from our country from Mumbai and Kerala. Despite being a tertiary care referral center, we knew how underprepared we were. Uncertainty, fear, denial existed both among doctors and administrators till we came across our first patient.

On March 18, 2020, a lady doctor of Indian origin, practising in London walked into our infectious disease unit asking to be tested for COVID-19 and that she needed to be quarantined. Back in London, she was taking care of patients with COVID-19, when a family emergency had prompted her visit to Chandigarh. She had self-isolated herself after reaching but developed symptoms after 5 days.

As expected, she tested positive and was admitted in the isolation facility.

This was a beginning of not a doctor-patient relationship but instead she guided us through our preparations for the upcoming pandemic. Through telephonic communications, she helped us plan and prepare ourselves for the next 14 days. Daily discussions followed more about our next steps and organization rather than her own health.

Slowly, she became the "go to guru" as we discussed out strategies, personal protective equipment (PPE) used, and
${ }^{1,3-5}$ Department of Internal Medicine, Postgraduate Institute of Medical Education and Research, Chandigarh, India

${ }^{2}$ Advanced Paediatrics Centre, Department of Paediatrics, Postgraduate Institute of Medical Education and Research, Chandigarh, India

Corresponding Author: Vikas Suri, Department of Internal Medicine, Postgraduate Institute of Medical Education and Research, Chandigarh, India, Phone: +91 9914209683, e-mail: surivikas9479@gmail.com

How to cite this article: Suri V, Suri D, Bhalla A, et al. A Good Samaritan: A Patient, a Colleague, or a Mentor. J Postgrad Med Edu Res 2020;54(3):141. Source of support: Nil

Conflict of interest: None

treatment guidelines. She made us realize how under-equipped we were and how things could change over days. Her experience helped us in expediting our actions, need to create more space, and above all start training the healthcare professionals on use of PPE.

I must add, she was self-monitoring herself, prevented even the nurses to enter and assist her, would record her own vitals, and had absolutely no fuss over the hospital food and hygiene, which was far from the western standards.

She came in as a patient but was probably God sent and left as a friend and a mentor.

A good Samaritan indeed.

(O) The Author(s). 2020 Open Access This article is distributed under the terms of the Creative Commons Attribution 4.0 International License (https://creativecommons. org/licenses/by-nc/4.0/), which permits unrestricted use, distribution, and non-commercial reproduction in any medium, provided you give appropriate credit to the original author(s) and the source, provide a link to the Creative Commons license, and indicate if changes were made. The Creative Commons Public Domain Dedication waiver (http://creativecommons.org/publicdomain/zero/1.0/) applies to the data made available in this article, unless otherwise stated. 